Comparison of Three Methods of Existential Psychotherapy, Individual, Group and Combined To Increase Marital Satisfaction

\author{
Azadeh Mahvelati ${ }^{1 *}$, MahSima PourShahriari ${ }^{2}$, Bahram Ali Ghanbari Hashem \\ Abadi $^{3}$, Zohreh Sepehri Shamlou ${ }^{4}$
}

\title{
ABSTRACT
}

The purpose of the present study is to investigate the effectiveness of three: individual group and combined methods of psychotherapy based on the existential approach, in order to compare the increase in marital satisfaction of married women. The method used by the authors of this study was the Single Subject Assessment A-B. The statistical society of this study consisted of married women living in Mashhad's 9th municipal district of Iran. The study's sample selection followed a non-random-available method. Study's tools consisted of demographic questionnaire, cognitive interviews and analog questions. Data analysis was conducted by means of presenting charts and graphs and clinical significance. Investigating the findings of analog questions indicated that combined method of existential psychotherapy is more effective in increasing marital satisfaction than group and individual existential therapy, and that group existential psychotherapy is more effective than individual existential therapy. Also, our follow up investigation, three months after the interventions showed that the effects of combined method of the end of therapy on married women lasted longer than individual and group methods of existential psychotherapy, also the effects of individual method of existential psychotherapy lasted longer than group method of existential therapy.

Keywords: Effectiveness, individual group and combined methods of existential therapy, marital satisfaction, single subject assessment $A-B$

\footnotetext{
${ }^{1} \mathrm{PhD}$ Student of Counseling at Al-Zahra University of Tehran, Tehran, Iran

${ }^{2}$ Faculty Member of Educational Sciences and Psychology Department of Al-Zahra University of Tehran, Tehran, Iran

${ }^{3}$ Faculty Member of Educational Sciences and Psychology Dept. of Ferdowsi University of Mashahad, Mashahad, Iran

${ }^{4}$ Faculty Member of Educational Sciences and Psychology Dept. of Ferdowsi University of Mashahad, Mashahad, Iran

*Responding Author

Received: February 23, 2017; Revision Received: March 19, 2017; Accepted: March 23, 2017

(C) 2017 Mahvelati A, Shahriari M, Abadi G, Shamlou Z; licensee IJIP. This is an Open Access Research distributed under the terms of the Creative Commons Attribution License (www.creativecommons.org/licenses/by/2.0), which permits unrestricted use, distribution, and reproduction in any Medium, provided the original work is properly cited.
} 


\section{Comparison of Three Methods of Existential Psychotherapy, Individual, Group and Combined To Increase Marital Satisfaction}

Before the $7^{\text {th }}$ decade of the $20^{\text {th }}$ century, the focal point of most studies conducted about family was divorce and its social-psychological effects on family members. However, from that decade on, scholars' attention shifted toward the issue of marital dissatisfaction and finding ways to increase marital satisfaction. The term marital satisfaction which refers to the mental assessment and the feelings of couples toward each other in marital relationship is the tangible feeling of satisfaction, pleasure and enjoyment experienced by the husband or wife when assessing the overall state of their marriage. In their study on 800 participants, Shumway and others realized that 65 percent of people have ranked their family problems as significant or severe. Olson and others' study found the correlation coefficient between marital satisfaction and family satisfaction to be about 70 percent, and the correlation coefficient between family satisfaction and life satisfaction to be approximately 67 percent. In other words: the health of society and family is related to the degree of people's marital satisfaction.

Scholars have also found that the negative effects of conflict (anger, hatred, unhappiness and fear) in couples' interactions is related to the amount of quarrels and fights between them, it is because as the amount of conflicts and dissatisfaction between couples rises the harder it becomes for them to live together and this might push them toward divorce. Investigation on the statistics of the United States indicates that 97 percent of adults in that country marry at least once during their lifetime. However, one out of four of those marriages end in divorce. Recently, the divorce rate in Iran has experienced a 2 percent rise. According to Husain Nayeri, the managing director of Khorasan Razavi's Births, Deaths and Marriage Registration Office with the divorce rate of 2.6 in a thousand in 2013, that province has the highest rate of registered divorce in the country. In addition, divorce which is a social phenomenon not only creates crisis for the divorcees but also traumatizes their children as much as their deaths might have traumatized them.

Moreover, many studies have shown that marital dissatisfaction can negatively affect couples' mental and physical health. The studies of Levinger and Hutson indicates that many marriages experience a time of significant disorderliness which puts one or both partners in the danger of developing mental disorders (e.g. anxiety, depression). Marital and family problems might lead to the development of disorders such as anxiety, depression, bipolar disorder, immune system disorders, children and adolescent aggression, eating disorders and alcoholism and also physical disorders such as heart disease. Marital conflicts might even create behavioral and psychological problems in children such as depression and even suicide. Marital dissatisfaction negatively affects children's general health and parents and child interactions. Children of unhappy marriages tend to experience autonomic stimulations and severe anxiety in their interactions with their parents. 


\section{Comparison of Three Methods of Existential Psychotherapy, Individual, Group and Combined To Increase Marital Satisfaction}

Today's science of psychology hugely investigates marital issues and conflicts. Constructive, systematic, guiding, relationship, cognitive, behavioral, truth therapy and also existential approaches are among the approaches that try to analyze and eliminate marital problems. Studies' antecedents of therapeutic interventions support the effectiveness and reliability of the system of family therapy. According to many studies, different approaches for couple therapy have average or significant statistical effects and often clinical ones. In addition, many studies testify to the positive effects of existential psychotherapy on different demographics and different problems. Corsini and Wedding (2011), suggest that many methods and principles of the existential approach are applicable for working with couples, families and groups. The family and couple therapy approach which was developed by Lantz is among those methods that its application might be beneficial in the mentioned subject.

In the existential psychotherapy, four basic assumptions are considered that can be used on patients in individual and group therapies. Those assumptions consist of: life and death, freedom, responsibility, the choice between isolationism and love making and finally seeking meaning and meaninglessness. In individual method of existential psychotherapy, the mentioned pattern not only focuses on the relationship between family members but also considers the experiences of each person from his/her own existence. In group method of existential psychotherapy, one or sometimes two therapists sit with eight to fifteen participants, and by following the mentioned pattern analyze participants subjectively, emotionally and psychologically in order to find a good solution for their problems. Participants also try to be as genuine as possible through an inter-individual relationship. The combined method of psychotherapy is an exclusive therapy and is not a system in which individual psychotherapy would be added to group therapy, and also does not mean that the therapist would see each participants of group therapy individually, rather, its purpose is to identify those who need more help in order to offer extra help to them. Sometimes, in order to understand interventional behavior and the distinct relationships between group members accurately, a therapist must see each of them individually, such two purpose review, might help the progress of the group as well.

Existential psychotherapists tend to encourage their patients to change the chief worldview and philosophy of their life. They mostly focus on family members' ability to extort creativity, freedom, bravery, flexibility, finding meaning and challenging life and its limitations. Therefore, helping couples to recognize, get involve, change and extend real patterns here and now can work as a facilitator for freedom and can extend the ability of taking responsibilities. As Ventares (1999) states:” Existential counseling is probably the most beneficial approach to help therapy seekers of most cultures, so they could find meaning and coordination in their life. This is due to this approach's focus on peoples' serious concerns such as love, anxiety, enduring pain and death. 


\section{Comparison of Three Methods of Existential Psychotherapy, Individual, Group and Combined To Increase Marital Satisfaction}

Studies conducted on applying existential approach for the purpose of increasing marital satisfaction have indicated its effectiveness. In their study, Lantz and Gregor applied the Existential Trauma Therapy (ETT) on patients recovering from heart attack based on the single subject method. Their findings indicate that such therapeutic method is indeed very useful especially when combined with individual, couple and family therapy methods. Richardson, Golden Kreutz and Anderson, Jim (2006), have also used the existential therapy psychotherapy approach in order to test its effectiveness on women suffering from breast cancer. Their findings displayed this approach's effectiveness in changing those women's views about cancer and life and in optimizing their family and marital performance.

Abdeh Khodaie (2008) has also conducted an study on this subject titled "Investigating and Comparing the Degree of Effectiveness of Existential Group Therapy and Cognitive Behavioral Group Therapy on Increasing Marital Satisfaction" He has reported both approaches to be effective on increasing marital satisfaction, but in his follow up section has named existential approach as the one with more lasting effect. In his study on the effectiveness of existential group psychotherapy for increasing marital satisfaction in married women, Razi (2011), has also reported the approach's effectiveness. In addition to those, in a study titled "A Comparison of the Effectiveness of Existential and Cognitive-Behavioral individual - Group Therapy on Fear" Dogahe, Muhammad Khani and Dowlat-Shahi (2012), proved both interventional approaches to be equally effective. Zard -Khane, Khodayari Fard, Afrouz, Sohrabi, Yunesi, Bonab and their colleagues (2009), have also reported the effectiveness of combined interventions compared to individual and group ones for reducing psycho cognitive disorders in prisoners.

A huge spectrum of couples who seek counseling, have often used many other solutions and turned to a professional as their last effort. Such attitude might help the therapist to determine what he/she should seek in his/her patients. It is based on such theoretical viewpoint that the therapist offers his chief therapy assumptions. Even though many studies have been conducted about the effectiveness of different approaches for increasing marital satisfaction in married women, however, the existential approach, despite its rich infrastructure has rarely been studied. Also, finding an approach which would produce the best result in the shortest time is of upmost importance. Many foreign and home studies have been currently conducted on comparing individual and group therapy using different approaches, however investigating the effectiveness of simultaneous therapy meaning the combined method of individual and group therapy and comparing them together has been hugely ignored. Therefore, this study aims to investigate the effectiveness of three methods of individual, group and combined psychotherapy on increasing marital satisfaction in married women and to compare the longevity of their effects three months after the interventions. It is worth mentioning that covering this subject might introduce efficient methods and approaches for many similar clinical conditions. 


\section{Comparison of Three Methods of Existential Psychotherapy, Individual, Group and Combined To Increase Marital Satisfaction}

\section{Study's Main Hypotheses}

1. Individual psychotherapy based on existential approach would increase marital satisfaction of married women.

2. Group psychotherapy based on existential approach would increase marital satisfaction of married women.

3. Combined psychotherapy therapy based on existential approach would increase marital satisfaction of married women.

4. The effectiveness of each three psychotherapy methods of individual, group and combined on marital satisfaction is different,

\section{Study's Secondary Hypotheses}

1. Individual psychotherapy based on existential approach has a long lasting effect on marital satisfaction of married women.

2. Group psychotherapy based on existential approach has a long lasting effect on marital satisfaction of married women.

3. Combined psychotherapy therapy based on existential approach has a long lasting effect on marital satisfaction of married women.

4. The longevity of effectiveness of each three psychotherapy methods of individual, group and combined on marital satisfaction is different,

\section{METHODOLOGY}

The statistical society of this study consisted of married women living in Mashhad's 9th municipal district, whom volunteered to participate in the study after reading the notification of participant recruit for a study and all of them were motivated to increase their marital satisfaction. The study's sample selection followed a non-random-available method; this was due to the various restrictions which barred us from random sampling. Nevertheless we did our best to choose the most random participants out of those preselected. Therefore, firstly we evaluated the participants in terms of their degree of intelligence (due to the deep concepts of existential approach), living away from their husbands, having severe physical or mental disorders, and the lack of receiving current of cognitive psychotherapy, and selected 50 volunteers to participate in the study. Then, due to the single subject assessment nature of the study we selected 10 people out of that 50 in order to control other interventional variables of the study. The mentioned 10 participants were selected with the advice of the expert colleagues of this study. The criteria for singling out the 10 last volunteers was : acquiring point 3 in answering the analog question about the evaluation of their marital satisfaction, being between the age range of 35 to 40, being married for 17 to 20 years, having two children, having a high school diploma and belonging to the middle class of society. 


\section{Comparison of Three Methods of Existential Psychotherapy, Individual, Group and Combined To Increase Marital Satisfaction}

In the next stage, we chose 3 people out of that 10 singled out participants following a random simple selection approach. Then we randomly placed one of them in the individual psychotherapy group, one in group psychotherapy group and one in combined psychotherapy group. The assessment of the experiment's individual method group was carried out weekly in twelve, 45 minutes long sessions of individual therapy based on the existential approach, the assessment of the single subject of the group therapy method was carried out weekly in twelve , 2 hours long sessions of group therapy based on the existential approach , finally the assessment of the single subject of the combined therapy method was carried out weekly in twelve , 45 minutes long sessions of individual therapy and weekly twelve, 2 hours long sessions of group therapy based on the existential approach. Since there was a need for a psychotherapy group in order to increase the effectiveness of group psychotherapy, 10 volunteers were chosen to be in that group after a psycho- cognitive interview with the first 50 people. Next, the target participants who were previously chosen to investigate the effectiveness of group and combined existential psychotherapy joined the group and the group began its work with 12 participants and one psychotherapist. However, by the end of the study the number of participants shrank to 10 (one person after the first session and one person after the fourth exited the group).

The method of this study was the Single Subject Assessment A-B, whose purpose is applicatory and developmental. Psychotherapists and expert specialists prefer this method due to its inexpensiveness and because it does not demand a lot of time and last but not least because it is underlying philosophy corresponds to the mind set of Psychotherapists and expert specialists, this is because these methods tend to focus on people's complexity and uniqueness.

Experimental designs of single subject studies consist of: such studies who investigate the effectiveness of a therapy or experimental interventions on a subject. Technically speaking, all single subject designs in non-random experimental designs are considered as a single unit in which self assessment would be considered as its own group's control tool. The A-B design starts with a series of "basic line measurements" and the first experimental intervention will be applied after that. We are dealing with distinct symbols in such domain. A would be held as the basic line or the hands-off stage and B would represent therapies or various experimental interventions.

Since our study's purpose was to investigate the effectiveness of three: individual group and combined methods of psychotherapy on increasing marriage satisfaction of married women, thus we first operationally defined marital satisfaction which is the study's dependent variable. In this study we considered the quantity of participants' points in answering the analog question of "Rate your weekly marital satisfaction from 0 to 10" as the ratio of their marital satisfaction (the higher the point, the higher the marital satisfaction). The validity of the point given by participants was verified through psycho cognitive interviews. In this method, first we applied 


\section{Comparison of Three Methods of Existential Psychotherapy, Individual, Group and Combined To Increase Marital Satisfaction}

our chosen intervention which was individual, group and combined existential psychotherapy on the target participant from the point A (analog question point 3), then in the B section the reduction in abundance, severity of the problem and the effectiveness of interventions was analyzed.

In order to gather enough data, we've asked the analog question before the onset of each session and also during them and recorded participants' answers to it. Then, we draw chart or figures using the collected data. The analog question was again asked and the psycho-cognitive interview was carried out 3 months after the end of the interventions in order to investigate the sustainability of the effects of the three therapy methods.

According to Bugental (2009), the individual existential therapy method consists of the following items: the first aspect which is a three item assessment. First the psychotherapists' assessment of the problem and whether it can be limited to certain domains or it can clearly expressed? Next is the psychotherapist's assessment of the urgency (pain and anxiety) of the patients' problem. Whether their ego has the sufficient strength to endure a complex approach, finally psychotherapist's assessment of whether the patients' ego has an efficient performance that would support them through a complex investigation. Before taking the first step the mentioned conditions should be me and the number of sessions should be specified and agreed on. The Second Aspect: This involves encouraging patients to list their concerns. Then the psychotherapist attempts to explain the issues of the patients clearly and without any misrepresentation or worry. The Third Aspect: this involves teaching the process of investigation and searching. This stage includes teaching the patients to confront their problems deeply and to focus on them. The Fourth Aspect: this involves understanding the resistance of the patients. As the patient continues to dig deep they might display some resistance, in this stage they would be encouraged to write down the process and begin their investigation anew. Due to the mentioned resistance, a meaningful change might not occur and the change occurred would be probably shallow and unsustainable. It is necessary for the patients to understand this. In other words the patients might not understand the degree of this short time activates and might consider them to be therapy limitations. The Fifth Aspect: this involves deepening the therapy. In this stage two parameters are of upmost importance and should be repeatedly explained to the patients. First: restraining needs must be recognized and should not be ignored. Second: actions that shift toward concerns must be identified. Considering these two parameters requires significant therapy skills. Without the structure, this process might accidentally lead to beneficial changes in the following actions. The Sixth Aspect: also known as the final aspect. In this stage patients need to view their final session as the conclusion, helping the patients to reflect what they have gained during the therapy and explaining the matters not understood by them is recommended in this stage. 


\section{Comparison of Three Methods of Existential Psychotherapy, Individual, Group and Combined To Increase Marital Satisfaction}

A person who received combined existential psychotherapy from a single therapist (researcher), had benefited from both individual and group therapy as well, and this schedule was carried out on a regular basis. Our group existential therapy was mostly based on James's (2005) views, except for group's special rules such as: informing group members about group progress, obeying group rules such as : keeping secrets, not interrupting others' speech, listening to others etc. the content of individual and group session was based on the basic principles of existential approach which consisted if : existential analysis of openness and self expression, introducing the psycho-cognitive concepts of freedom of choice, informing about the consequences of freedom of choice in marital relationships, explaining the role of taking responsibilities in self

growth and the growth of marital relations, encouraging new decisions and taking responsibility for the choices made, being aware of your partner's internal world, and trying to get used and coordinated with your partner's way of being, understanding the incompatibility of isolationism and closeness with others, understanding the role of closeness in enduring loneliness, reducing unhealthy attachment in marital relations and helping to gain individuality in a fruitful relationship, reminding and investigating the hidden meanings of marital relations, explaining love as need for getting united with the universe, explaining honest and humane kindness and its effect on maintaining a satisfactory marital relationship. The content of each session was based on the participant's needs and followed the advice of the expert colleagues of the study in accordance with the above concepts. It is worth mentioning that the above concepts were not applied in a particular order.

\section{Materials}

The measuring tools of the present study consisted of a demographic questionnaire, psychocognitive interviews and an analog question.

A: Demographic Questionnaire: In order to coordinate the singled out participants with each other and to increase data compatibility, we've used a self-made questionnaire following the advice of the expert colleagues of the study. The mentioned questionnaire asked for information such as: participants' age, years of marriage, number of children, degree of education, place of residence and participants' social-economic class.

B: Psycho-Cognitive Interview: In order to evaluate the singled out participants we have conducted a psycho-cognitive interview with them following the advice of the expert colleagues of the study. The mentioned interview consisted of: investigating volunteers' motive, their level of intelligence (due to the complex concepts of existential approach), whether they lived with their husbands, and the existence of a severe physical ailment and whether they were currently receiving therapy. Additionally, we conducted a secondary psycho-cognitive interview at the beginning of each therapy session and the follow up session after participants answered the analog question and Self assessed the ratio of their marital satisfaction in order to verify their score. The mentioned interview involved asking about the reason why their score has increased or decreased. 


\section{Comparison of Three Methods of Existential Psychotherapy, Individual, Group and Combined To Increase Marital Satisfaction}

C: The Analog Question: In order to investigate the marital satisfaction of the single subject, we came up with an analog question which asked the participants to rate their weekly marital satisfaction from 0 to 10 (we assumed a higher score as higher marital satisfaction) this was done following the advice of the expert colleagues of the study.

\section{Findings}

\section{Demographic Data}

1. The single subject of the individual existential therapy was a Mrs. A, who was 37 years of age, was married for 17 years, had a high school Diploma, had 2 children, and was coming from a middle social-economic class. She had rated her marital satisfaction as 3 prior the onset of therapy.

2. The single subject of the group existential therapy was a Mrs. A, who was 36 years of age, was married for 18 years, had a high school Diploma, had 2 children, and was coming from a middle social-economic class. . She had rated her marital satisfaction as 3 prior the onset of therapy.

3. The single subject of the combined existential therapy was a Mrs. S, who was 35 years of age, was married for 19 years, had a high school Diploma, had 2 children, and was coming from a middle social-economic class. . She had rated her marital satisfaction as 3 prior the onset of therapy.

\section{Analysis Data}

In order to investigate the effectiveness and sustainability of individual, group ad combined existential psychotherapy and to compare the above three methods with each other, we have analyzed the scores acquired from asking the analog question. Table 1, shows the scores of the analog question that was the ratio of marital satisfaction, in a separate manner.

\begin{tabular}{|c|c|c|c|c|c|c|c|c|c|c|c|c|c|}
\hline & $\begin{array}{l}\text { Sessio } \\
\text { n } 1\end{array}$ & $\begin{array}{l}\text { Sessi } \\
\text { on } 2\end{array}$ & $\begin{array}{c}\text { Sessio } \\
\text { n } 3\end{array}$ & $\begin{array}{c}\text { Sessio } \\
\text { n } 4\end{array}$ & $\begin{array}{c}\text { Sessio } \\
\text { n } 5\end{array}$ & $\begin{array}{l}\text { Sessio } \\
\text { n } 6\end{array}$ & $\begin{array}{l}\text { Sessio } \\
\text { n } 7\end{array}$ & $\begin{array}{l}\text { Sessio } \\
\text { n } 8\end{array}$ & $\begin{array}{l}\text { Sessio } \\
\text { n } 9\end{array}$ & $\begin{array}{l}\text { Sessio } \\
\text { n } 10\end{array}$ & $\begin{array}{l}\text { Sessio } \\
\text { n } 11\end{array}$ & $\begin{array}{c}\text { Sessio } \\
\text { n } 12\end{array}$ & $\begin{array}{l}\text { Follo } \\
\text { w Up }\end{array}$ \\
\hline Individual & 3 & 4 & 5 & 5 & 5 & 6 & 5 & 5 & 6 & 6 & 7 & 7 & 7 \\
\hline Combined & 3 & 5 & 4 & 4 & 5 & 4 & 5 & 7 & 8 & 8 & 9 & 9 & 8 \\
\hline
\end{tabular}

Table 1: Self report scores of the analog question about the ratio of marital satisfaction

Chart 1, shows participants' score in answering the analog question asked at the beginning of each session about the ratio of their marital satisfaction in order to facilitate the analysis process. It is worth mentioning that the mentioned chart shows the scores of individual, group and combined psychotherapies separately. 


\section{Comparison of Three Methods of Existential Psychotherapy, Individual, Group and Combined To Increase Marital Satisfaction}

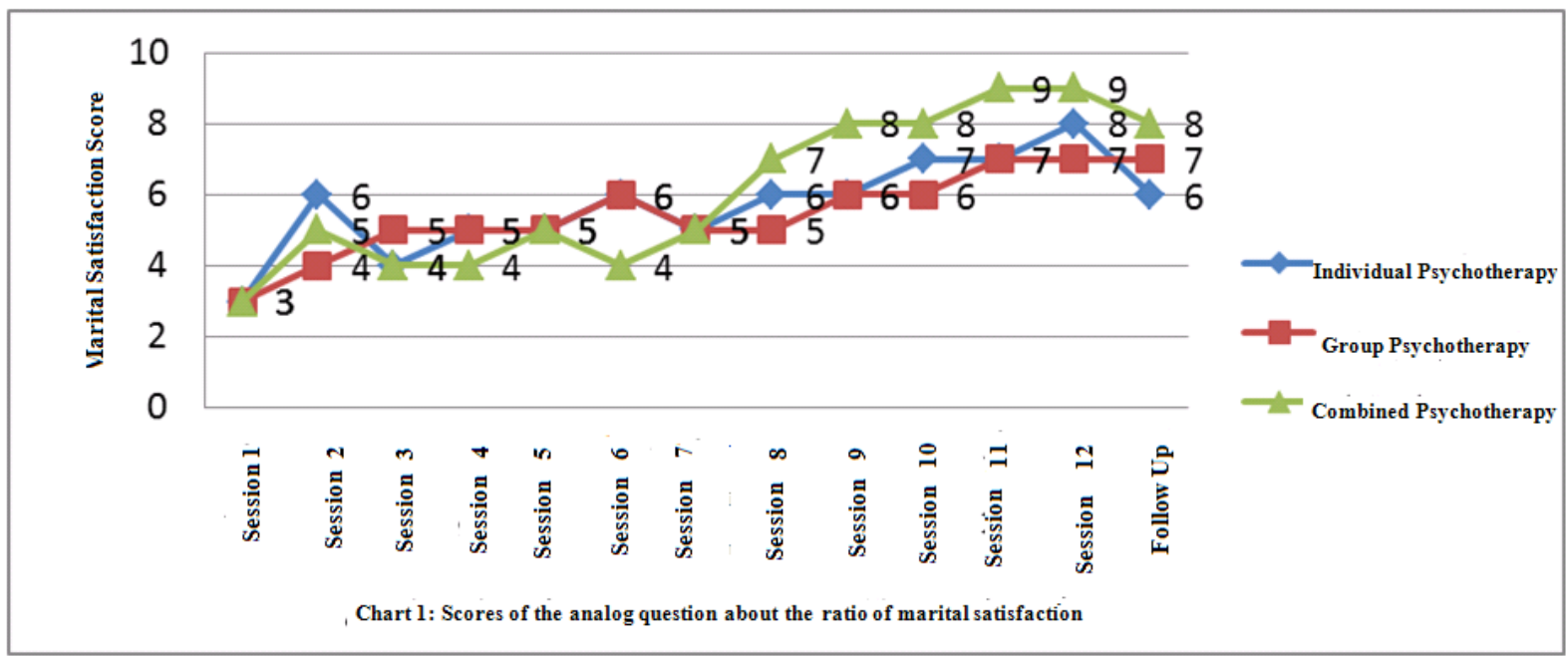

As you can see on Table and Chart 1, the single subject of individual existential psychotherapy, began her treatment from the basic line A, with the score of 3. However by the end of treatment and in the finish line B or the twelfth session, (B1: 7) her satisfaction has increased $(3<7)$. Therefore the first main hypothesis of the study regarding the effectiveness of individual existential psychotherapy on increasing marriage satisfaction was verified.

Also, as you can see the marriage satisfaction score in the follow up line of B2 or 3 months after the last session was greater compared to the earlier line of $A(3<7)$. Thus, the secondary hypothesis of the study regarding the longer lasting effects of individual existential psychotherapy treatments was verified.

Investigation revealed that the above hypothesis was in accordance with study results of Lantz and Gregor (2003) and Richardson, Golden Kreutz, Anderson and Jim (2006).

Moreover, as you can see on Table and Chart 1, the single subject of individual existential psychotherapy, began her treatment from the basic line A, with the score of 3 . However by the end of treatment and in the finish line of B or the twelfth session, (B1: 8) her satisfaction has increased $(3<8)$. Therefore the second main hypothesis of the study regarding the effect of group existential psychotherapy on increasing marriage satisfaction was also verified. Also, as you can see the marriage satisfaction score in the follow up line of B2 or 3 months after the last session was greater compared to the earlier line of $A(3<6)$. Thus, the second secondary hypothesis of the study regarding the longer lasting effects of group existential psychotherapy treatments was verified.

Investigation revealed that the above hypothesis was in accordance with study results of Abdeh Khodaie (2008) and Razi (2011) that also found the existential psychotherapy methods to be effective for increasing marital satisfaction.

(c) The International Journal of Indian Psychology, ISSN 2348-5396 (e)| ISSN: 2349-3429 (p) | 


\section{Comparison of Three Methods of Existential Psychotherapy, Individual, Group and Combined To Increase Marital Satisfaction}

Also, as you can see on Table and Chart 1, the single subject of combined existential psychotherapy, began her treatment from the basic line A, with the score of 3. However by the end of treatment and in the finish line of B or the twelfth session, (B1: 9) her satisfaction has increased $(3<9)$. Therefore the third main hypothesis of the study regarding the effect of combined existential psychotherapy on increasing marriage satisfaction was also verified. Also, as you can see the marriage satisfaction score in the follow up line of B2 or 3 months after the last session was greater compared to the earlier line of $\mathrm{A}(3<8)$. Thus, the third secondary hypothesis of the study regarding the longer lasting effects of combined existential psychotherapy treatments was verified as well.

Investigation revealed that the above hypothesis was in accordance with study results of ZarKhaneh, Khdayari Fard, Afrouz, Sohrabi, Yunesi, Bonab, Shokouhi, Faghihi, Beh Pajouh, Abedini, Rostami, Ismaili, Motevali and Ahmadi (2009).

In addition to those, as you saw on Table and Chart 1, all single subjects of combined existential psychotherapy, began their treatments from the basic line A, with the score of 3.However, by the end of the twelfth session B1, participant of combined psychotherapy have reported a higher degree of marital satisfaction compared to the participant of group $(8<9)$ and individual psychotherapy $(7<9)$. Therefore the last main hypothesis of the study regarding the difference between three methods of individual, group and combined existential psychotherapy was verified. Also, comparing the effectiveness of the mentioned three methods of treatment $\mathrm{s}$ in the follow up line of B2 reveals that the participant in combined existential psychotherapy had a greater marital satisfaction compared to individual $7<8$ and group $6<8$ psychotherapy participants, and the participant of individual psychotherapy had also reported a higher degree of marital satisfaction compared to the participant of group psychotherapy $6<7$. Thus, our last secondary hypothesis regarding the differences between the longevity of the effects of three method of individual, group and combined existential psychotherapy was also verified.

Investigation revealed that the above hypothesis was not in accordance with study results of Do Gaheh , Muhammad Khani and Dowlat-Shahi (2012), but was in accordance with study results of Zar-Khaneh, Khdayari Fard, Afrouz, Sohrabi, Yunesi, Bonab, Shokouhi, Faghihi, Beh Pajouh, Abedini, Rostami, Ismaili, Motevali and Ahmadi (2009).

\section{DISCUSSION}

The present study was conducted due to the importance of marital relations and in order to present the best approach and therapy method for increasing martial satisfaction. Therefore, we chose the existential approach due to the humanistic nature of the study and the strong antecedents of using this approach for individual, group and combined psychotherapy. It is worth mentioning that in the investigation of the effectiveness and comparison of group psychotherapy

(c) The International Journal of Indian Psychology, ISSN 2348-5396 (e)| ISSN: 2349-3429 (p) | 195 


\section{Comparison of Three Methods of Existential Psychotherapy, Individual, Group and Combined To Increase Marital Satisfaction}

method, we focused only on the study results of the single subject of group psychotherapy as our main purpose of the study. Therefore we did not examine other findings of the group therapy experiment in details.

Investigating the effectiveness of therapy methods using result analysis by means of drawing charts and clinical significance of the marital satisfaction of all three single subjects of individual, group and combined psychotherapy revealed that they generally experienced a significant progress since the onset of their treatment. This proves the effectiveness of existential approach in increasing marital satisfaction. Perhaps this is due to the nature of this approach which allows the therapist to give his/her patient the freedom of choice and warn him/her that the main purpose of treatment is for him/her to face his/her anxieties. When the patient realizes this he/she senses fear which is tangible and real. Now, the patient has the chance to reduce his/her anxiety. Even though facing the anxiety caused by existential loneliness is a different, still many marriages and relationships break up. This is because in such case one person uses another merely to evade loneliness. Therefore accepting that we need closeness with others but we might not be able to do successfully, might help us deal with our existential loneliness. On the structure of personality, existential approach emphasizes the deep effects of everyday experiences and does not dwell on improving patient's past, rather it shatters the obstacle on the way of patient's decision making power in order to lead him/her toward autonomy. The product of existential psychotherapy would be a bold and strong person who is able to deal with responsibly, loneliness and anxiety in an efficient manner.

Moreover, in comparing therapy methods using result analysis through chart drawing and clinical significance we realized that right after the end of treatment and 3 months after the last session the participant of combined therapy has reported a higher ratio of marital satisfaction compared to individual and group therapy participants. This might be partly due to the psychotherapist's efforts in individual sessions to solve issues and eliminate the resistances that might create some problems in group sessions and, and partly due to the relief participants feel when meeting people with the same issues as them in groups and receive social feedback, something that might never occur in individual sessions. Therefore, the patient receiving combined psychotherapy might express more enthusiasm to continue her treatments.

The single subjects of combined and group therapy stated in the psycho-cognitive interview that they had felt hope, shared common concerns and experienced an increase in marital satisfactions while attending group psychotherapy. The single subject of combined existential therapy counted factors such as self revelation, revealing a secret to group members and the way of selfexpressions in the group as effective factors in increasing her marital satisfaction. Participants of existential group therapy face some of their concerns such as their inability to form meaningful relationships with others, and therefore they identify the obstacles on the way of forming 


\section{Comparison of Three Methods of Existential Psychotherapy, Individual, Group and Combined To Increase Marital Satisfaction}

relationships with others in the real world. Such method of therapy would be very effective for someone who has freed him/herself from past restrictions and is in need of replacing novel individual patterns in his/her life (the reason we used middle age participants). During such therapy these people tried to let go of family designs that had worked well for sometime but have become problematic, in order to create new meanings in their lives.

Moreover, as you just saw, immediately after the last session the single subject of existential group therapy expressed a higher degree of marital satisfaction compared to the individual existential psychotherapy single subject. This is perhaps due to some particular factors of group psychotherapy such as: harmony motivated learning, generality, being optimistic about the treatment, helping other people, observational learning and facilitating the release of excitement that might have sped up the progress of the participant of group psychotherapy. Psychotherapists used to put more value on individual psychotherapy and would consider group psychotherapy as a secondary and less effective option. However, the effectiveness of group therapy has become clear today. Nevertheless, in the follow up session after the treatment the participant of individual psychotherapy reported a greater degree of marital satisfaction compared to the participant of group psychotherapy sessions. Perhaps this indicates that group psychotherapy might create faster results, however, individual sessions have more depth. Thus they leave a longer lasting effect on patients. Nevertheless, uncontrolled factors might have also played a role in producing such results.

The single subject of individual existential psychotherapy reported a slower process compared to the other single subjects, however, as we approached the last session she showed a significant improvement, not to forget that her treatment had a longer lasting effect compared to the group psychotherapy single subject. In her psycho-cognitive interview, three months after her last session of psychotherapy, the single subject of individual existential psychotherapy stated factors such as gaining self confidence, self acceptance, acquiring insight to her problems and accepting life's limitations as the reason for her improvement. On the other hand, despite psychotherapists' confirmation of the slow process of progress in individual psychotherapy however, they repeatedly remind the patients of the following: "You are not doing what you want to do. "This way they inform patients about the two important items of determination: wanting and doing something about it. Such deep realization might help the patients to face their problems honestly and might make them more responsible.

\section{CONCLUSION}

Moreover, in comparing therapy methods using result analysis through chart drawing and clinical significance we realized that right after the end of treatment and 3 months after the last session the participant of combined therapy has reported a higher ratio of marital satisfaction compared to individual and group therapy participants. Despite the results of this study regarding 


\section{Comparison of Three Methods of Existential Psychotherapy, Individual, Group and Combined To Increase Marital Satisfaction}

the effectiveness of combined existential psychotherapy on increasing marital satisfaction of married women, it is necessary to view these results as early and not absolute. Therefore, applying such method in other experimental groups in form of single subject designs with longer sessions and in single subject designs with more psychotherapists and in form of couple therapy would be recommended.

Moreover, psychotherapist must note the fact that in combined psychotherapy (simultaneous individual and group psychotherapy), therapists' role would necessarily change and would become more complex. Psychotherapists in group sessions have more freedom to ask questions, guess blindly, ask general and comprehensive questions, encourage group members to express their feelings toward one another or about some other events, while, in combined psychotherapy the therapist knows those information already so he/she should be careful not to ask questions whose answers he/she already knows. In such method of psychotherapy, the therapist realizes that he/she is less active toward the combined psychotherapy patient, something that makes offering both form of therapies more challenging, because the therapist should show two sides of her/himself in such therapies, meaning he/she should be more informal and relaxed In group therapy while trying to stay formal in individual sessions.

It is worth mentioning that the participant of individual existential therapy was more intelligent compared to the single subjects of group and combined psychotherapy, something that made working with her more challenging, but in turn she had the strength to dig deep into her problems and face them head on. According to the psychotherapist the mentioned participants might have had better results if she would extend the numbers of her sessions to twenty, Therefore, we must not ignore the effects of individual, cultures differences, environmental conditions, the ability of the therapies or other uncontrolled factors when interpreting study results. Moreover, the findings of the present study should be interpreted with cautious due to its single subject nature and the its restricted sample (women between the ages 35-40, with two children, married for 1720 years, with a high school Diploma, living in Mashhad's $9^{\text {th }}$ municipal district, coming from the middle social-economy class) and its lack of control for disruptive variables such as cultural, family, intelligence and personality level. Even though, we did our best to control the condition as much as possible, however, full control has always proved difficult in humanistic and cognitive psychology experiments.

Lastly, since the effectiveness of individual, group and combine existential psychotherapy was verified in this study and because of married women's needed to increase their marital satisfaction, we recommend psychotherapists to consider these methods in their therapy programs. 
Comparison of Three Methods of Existential Psychotherapy, Individual, Group and Combined To Increase Marital Satisfaction

\section{Acknowledgments}

We appreciate and thank all the participants in this research project.

Conflict of Interests: The author declared no conflict of interests.

\section{REFERENCES}

Abde-Khodaie, Z, “ A Comparison of Two Methods of Group Existential Psychotherapy and Cognitive Psychotherapy on Increasing Marital Satisfaction in women” Masters degree Thesis, Mashhad, Ferdowsi University of Mashhad 1999

Barker P. “Basic Family Therapy”. 2th Edition. Blackwell publishing. 2007.

Beach S. R. H., Fincham F. D. \& Katz J. "Marital Therapy in the Treatment of Depression: Toward a Third Generation of Therapy and Research". Clinical Psychology Review, 1998. 18(6): 661-635.

Bernstein , F. H, Bernstein M.T, “ Couple Counseling: Identifying and Treating Marital Disorders”, Translated by: Hamid Reza Sohrabi, Rasa Publications, 2003

Biaban-Gard, A, “ Adolescent Psychology”, Tehran, Farhang E Islami Publishing Company, 2005

Bookwala J, Sobin J, \& Zadaniuk B. "Gender and Aggression in Marital Relationships: A LifeSpan Perspective. Sex Roles” 2005. 52: 797-5060.

Corsini R. J. “The Dictionary of Psychology.” Philadelphia: Taylor \& Francis group., 1999.

Corsini R. J., Wedding D. “Current Psychotherapies”. 9th. Inc: F. E., peacock publishers. 2011.

Coyne J, Thompson R, \& Palmer S. "Marital Quality, Coping with Conflict, Marital Complains, and Affection in Couples with Depressed Wife"., 2002.

Doss B, Simpson L, \& Christensen A. "Why Do Couples Seek Marital Therapy? " Professional Psychology: Research and Practice, 2004. 35(6), 608-6140.

Fincham F. "Marital Conflict: Correlates, Structure and Content", American Psychological society, 2003. 12-10.

Gerarad J. A. \& Buehier C. Marital conflict: Parent- child relations and youth maladjustment, Family Process, 2003. 38(1): 105-1160.

Glaser J. K., Fisher L. D, et al. "Marital Quality, Marital Disruptions, and Immune Function." Journal of family Issues, 1987. 49: 13-34.

Gottman J.M. “The Marriage Clinic: A Scientifically Based Marital Therapy” New York. 1999.

Gottman, J,M “ Seven Ethical Principles for a Successful Marriage” Translated by : Mehdi Gharache-Daghi, Tehran, Asim Publishing Co, 2007

Hamidi , F, “ Investigating the Relationship between the Styles of Attachment and Marital Satisfaction in Married Teaching Students” Family Studies Seasonal Magazine, 2007, : 3 (9), P: 443-453

Islami-Nasab, A, “ Group Psychotherapy”, Tehran, Heram Publishing Co, 1995 


\section{Comparison of Three Methods of Existential Psychotherapy, Individual, Group and Combined To Increase Marital Satisfaction}

James C. “Group Psychotherapy and Existential Concerns”: An Interview with Irvin Yalim. Journal of contemporary psychotherapy, 2005. 35., 16: 26- 370.

Kaar, A, "Family Therapy“, Translated by: Gholam-Reza Tabrizi, Mashhad, Marandiz Publishing Co, 2005

Kerry, J, "The Theories and Practices of Humanistic Group Counseling” , Translated by: Catayoun Daneshvarian, Tehran, Shokouh Publishing Co., 2009

Lantz J \&Gregoire T. “Couple Existential Psychotherapy and Myocardial Infarction: a Ten Year Evaluation Study". Contemporary family therapy, 2003. 25: 367-379.

Lantz J. “Depression, Existential Family Therapy, and Viktor Frankel’s Dimensional Ontology”, family therapy. 2001. 1:23.

Lantz J. "Research and Evaluation Issues in Existential Psychotherapy" Journal of Contemporary Psychotherapy, 2004. 4:34.

Miklowitz D. J., Goldstein M. J., Neuchterlein K. H., \& Duane J. A.” Family Factor and the Course of Bipolar Affective Disorder". Arch. Sex psychology, 1998. 45: 225-31.

Navabi Nejad, Sh, “ The Theories of Counseling and Group Psychotherapy” , First Edition, Tehran, Samt Publishing Company, 2004

Navabi Nejad, Sh, "The Theories of Group Counseling and Psychotherapy", Tehran, Samt Publishing Co, 2004

Nazari, A.M, Navabi Nejad, Sh, “ Investigating the Effects of Improvement Programs on Marital Satisfaction of Working Couples”, Counseling Studies Magazine, 2005, 4 (13):

P: 103-122

Razi, A, "Investigating the Effectiveness of Group Counseling on the Source of Control and Marital Satisfaction of Married Women between 20-45 Years of Age" Masters Degree Thesis, Tehran, University of Tehran

Rezaie Dogaheh, A, Muhammad Khani, P, Dowlat Shahi , B, "A Comparison of the Effectiveness of Existential and Cognitive-Behavioral individual - Group Therapy on Fear of Positive Evaluation”, Tavanbakhsi, 2012, P: 56-58

Richardson S. A., Golden-Kreutz D. M., Andersen B. L. \& Jim H. S. "Strategies Used in Coping with a Cancer Diagnosis Predict Meaning in Life for Survivors". Health Psychology, 2006. 25, 6: 753-761.

Sahebi, A, 2003, “ Study Method for Clinical Psychology”, Tehran, The Organization of Study and Publishing of Humanistic Sciences Books AKA SAMT

Sarmad, Z, Bazargan A, Hejazi , A, 2003, “ Study Methods for Behavioral Sciences” Agah Publishing Co.

Shadish W. R., Montgomery L. M., Wilson P, Wilson M. R. \& okwumakua T. "The Effects of Family and Marital Psychotherapies: A Meta Analysis”. Journal of counseling and clinical Psychology, 1993. 61-81.

Sharef, R.S, “ The Theories of Psychotherapy and Counseling “ Translated by: Mehrdad FirouzBakht, Tehran, Rasa Publishing Co, 2005 


\section{Comparison of Three Methods of Existential Psychotherapy, Individual, Group and Combined To Increase Marital Satisfaction}

Suls J. \& Bunde J. “Anger, anxiety, and Depression as Risk Factors for Cardiovascular Disease” The problems and implications of overlapping affective dispositions. Psychological Bulletin, 2005. 131(2): 260-300.

Vedadian, Z, “ The Effectiveness of Multifamily Group Therapy on Solving Parent-Child Conflicts and Reducing Children's Behavioral Issues”, Masters degree Thesis, Ferdowsi University of Mashhad 2011

Young M.E \& Long L.L. “Counseling and Therapy for Couples.” New York Brooks: cool Publisher Company. 1998.

Zarkhane, S, A, Khodayari Fard , M, Afrouz Gh, “ Investigating the Effectiveness Individual and Group of Cognitive Psychotherapy on the Psycho-Cognitive Health Of Rajaie Shahr Prison Inmates" Journal of Contemporary Psychology, Iranian Guild of \{Psychology, 2009, P: 9-1

\section{Website:}

SSAA.IR. 2014. Available at: https://www.sabteahval.ir/Default.aspx?tabid=4822_preg.htm Accessed Oct 21, 2014

SABTEAHVAL-KH.IR. 2014. Available at: http://www.sabteahval-kh.ir/Portals/47/9312/13.pdf_preg.htm Accessed Oct 23, 2014

How to cite this article: Mahvelati A, Shahriari M, Abadi G, Shamlou Z (2017), Comparison of Three Methods of Existential Psychotherapy, Individual, Group and Combined To Increase Marital Satisfaction, International Journal of Indian Psychology, Volume 4, Issue 2, No. 94, ISSN:2348-5396 (e), ISSN:2349-3429 (p), DIP:18.01.159/20170402, ISBN:978-1-365-84229-0 